\title{
ESTÁ ME CHAMANDO DE DOENTE? O DISCURSO MEDICALIZANTE DO TDAH NA ESCOLA: UMA REVISÃO
}

\author{
Ademir Henrique Manfre
}

Doutor em Educação pela Universidade Estadual Paulista - UNESP. Docente na Universidade do Oeste Paulista UNOESTE, Presidente Prudente, SP. E-mail: ademirmanfre@yahoo.com.br

\begin{abstract}
RESUMO
Este artigo é resultado de uma revisão bibliográfica realizada acerca do tema medicalização, instrumentalização do pensamento e educação escolar. Os questionamentos que potencializam esse debate são os seguintes: que conjunto de saberes e práticas institucionais nos têm levado a pensar que a administração medicamentosa em nossas crianças pode resolver as mazelas educacionais? Estamos transformando comportamentos tais como a desobediência, a distração, a inquietude, a impulsividade, a hiperatividade socialmente indesejados em patologias? Trata-se, portanto, de um ensaio teórico que procura elaborar possíveis encaminhamentos à medicalização da queixa de comportamento no contexto escolar brasileiro a partir de um ponto de vista crítico. Empreendemos nossas análises no entrecruzamento dos aportes teóricos advindos da crítica da medicalização da queixa escolar. Desse modo, os teóricos que sustentam a argumentação crítica à medicalização são: Moysés \& Collares (1996), Garrido (2010), Signor \& Santana (2016), Furtado (2014), Leonardi (2010), dentre outros. Em um primeiro momento, traçamos um percurso teórico a fim de situar o modo como a medicalização do escolar se apresenta no contexto do debate educacional brasileiro. Em seguida, evidenciamos os limites da medicalização da vida no campo escolar. Por fim, destacamos a necessidade de se pensar uma escola que problematize os chamados "problemas de aprendizagem", adotando uma postura crítica em relação à produção bibliográfica brasileira que associa "dificuldades de aprendizagem" à "doença". Essa proposta implica repensar o modo de relação com o saber institucionalizado e com o outro, construindo estratégias pedagógicas que acolham a multiplicidade de modos de ser que compõem cada indivíduo.
\end{abstract}

Palavras-chave: Educação. Medicalização. Formação Docente. TDAH.

\section{ARE YOU CALLING ME SICK? THE MEDICAL DISCURSE OF ADHD IN SCHOOL: A REVIEW}

\begin{abstract}
This article is the result of a bibliographical review on the topics: medicalization, instrumentalization of thought, and school education. The questions that promote this debate are: What set of institutional knowledge and practices have led us to think that medicine administration in our children solve the educational problems? Are we transforming behaviors such as disobedience, distraction, restlessness, impulsivity, and socially undesirable hyperactivity in pathologies? It is, therefore, a theoretical essay in which we elaborate some critics to the medicalization of the complaint of behavior in Brazilian school context. We ground our analysis on the interweaving of the theoretical contributions coming from the criticism of the medicalization of the school complaint. Theorists who support the critical argumentation of medicalization are: Moysés \& Collares (1996), Garrido (2010), Signor \& Santana (2016), Furtado (2014), Leonardi (2010), among others. At first, we draw a theoretical track in order to place the way in which the school medicalization presented in the context of the Brazilian educational debate. Next, we stress the limits of the medicalization of life in such context. Finally, we emphasize the importance to think about a type of school that problematizes the so-called "learning problems", adopting a critical position in relation to the Brazilian bibliographic production that relates "learning problems" of the "disease". Our proposal entails to rethink the way that the relationship between institutionalized knowledge and the other is made in a way of elaborating pedagogical strategies that accommodate the multiplicity of modes of being that make up each individual.
\end{abstract}

Keywords: Education. Medicalization. Teacher training. ADHD. 


\section{APRESENTAÇÃO DA PROBLEMÁTICA}

Tratar da temática medicalização e educação escolar implica analisar como se configuram, dentro de uma racionalidade instrumental medicalizante ${ }^{1}$, estratégias de administração da experiência ${ }^{2}$ em todas as suas instâncias.

Partindo dessa premissa e amparados em teóricos que estão na contramão da racionalidade instrumental medicalizante ${ }^{3}$, problematizamos a literatura científica que justifica as dificuldades de aprendizagem, os comportamentos classificados como desatentos, hiperativos e até indisciplinados como sintomas patológicos.

Assim, a investigação aqui proposta parte dos seguintes questionamentos: que conjunto de saberes e práticas institucionais nos têm levado a pensar que ao administrar remédios ${ }^{4}$ a nossas crianças, podemos solucionar as mazelas educacionais? De acordo com a literatura crítica que discute a medicalização do escolar, estamos transformando comportamentos, tais como a desobediência, a distração, a inquietude, a impulsividade e outras características socialmente indesejadas em patologias

Diante da amplitude que caracteriza a temática, os modos de subjetivação ${ }^{5}$ na

\footnotetext{
${ }^{1}$ Barros (2010, p. 91) anota que essa terminologia é proveniente do texto de Ivan Illich (1975) para conceituar o processo de "invasão crescente da medicina" em áreas da vida individual que passam a ser objeto da atenção médica, mesmo que não tenham "sinais ou sintomas de caráter mórbido ou patológico". Dito de outro modo, os chamados "desvios de conduta" tornam-se sintomas patológicos na medida em que a racionalidade instrumental médica adentra em todos os espaços da vida e se expande pelas diferentes práticas educativas.

${ }^{2}$ Tomamos como referência o conceito de experiência explorado por Larrosa (2002, p.21): "A experiência é o que nos passa, o que nos acontece, o que nos toca. Não o que se passa, não o que acontece, ou o que toca. A cada dia se passam muitas coisas, porém, ao mesmo tempo, quase nada nos acontece [...]. Walter Benjamin, em um texto célebre, já observava a pobreza de experiências que caracteriza o nosso mundo. Nunca se passam tantas coisas, mas a experiência é cada vez mais rara."

${ }^{3}$ Os teóricos que sustentam a argumentação crítica à medicalização são: Moysés \& Collares (1996), Garrido e Moysés (2010), Signor \& Santana (2016), Furtado (2014), Leonardi, Rubano e Assis (2010), dentre outros.

${ }^{4}$ Diante do exposto, resta aos professores buscar alternativas que são apresentadas no ambiente escolar como solução para os "problemas de comportamento" de forma a-histórica. O encaminhamento aos setores médicos é uma dessas alternativas, anota Signor \& Santana (2016). Assim, a inserção da medicina nos ambientes escolares torna-se a "pedra filosofal" para solucionar os problemas de comportamento dos/as alunos/as indisciplinados, mal-educados, desatentos e agressivos.

${ }^{5}$ Bezerra JR. (2010) desenvolve uma importante reflexão sobre os modos de subjetivação contemporâneos. Para o referido, a subjetividade é concebida como emergência histórica de processos em coerência com os processos sociais, culturais, econômicos,
}

contemporaneidade nos convocam a questionar a classificação da diversidade humana como patologia, transtorno ou algum tipo de desvio. É cada vez mais recorrente em nossa sociedade e, no caso específico da educação, dizer que uma criança não aprende e não se comporta adequadamente na escola devido a transtornos neurológicos que afetam o campo cognitivo, entendido como fundamental para o processo de ensino e aprendizagem.

Nessa exposição, interessa-nos, particularmente, discutir o Transtorno de Déficit de Atenção e Hiperatividade (TDAH), descrito pela literatura medicalizante como uma doença mental, pois, no entendimento da especialidade médica, nessa patologia, "lida-se mais com deficiências de estratégias cognitivas" (ROHDE; MATTOS, 2003, p. 186).

Inúmeras intervenções são indicadas como eficazes para abordar esse transtorno. Em especial, destacam-se as intervenções psicofarmacológicas e a Terapia Cognitivocomportamental $^{7}$ (TCC) que, desde a década de 1950, de acordo com as concepções medicalizantes, vêm crescendo em decorrência de estudos de casos controlados e de "pesquisas científicas".

Para que se tenha uma ideia mais acertada sobre esse pensamento, desenvolveremos as nossas reflexões em dois momentos. Em um primeiro momento, traçamos um percurso teórico a fim de situar o modo como a medicalização da queixa escolar se apresenta no contexto do debate educacional brasileiro. Por

midiáticos, tecnológicos que participam de sua constituição e funcionamento. Entre as formas de subjetivação na atualidade, o autor destaca a negação do sofrimento, a busca irrefreável da felicidade, a instrumentalização do pensamento e a administração da vida. Estaríamos, pois, diante do que Lasch (1983) denominou "cultura do narcisismo", na qual a subjetividade se concebe de forma autorreferida sem atentar para a existência do outro, associando consumo a individualismo na busca incessável do prazer. No que se refere ao debate medicamentoso na educação escolar, encontramos um modo de subjetivação de assujeitamento, de instrumentalização do pensar, de exclusão e intensificação de comportamentos patológicos.

6 De acordo com a literatura científica, "nas patologias caracterizadas por deficiências cognitivas, tendo o TDAH como um dos principais exemplos, encontram-se estratégias diferentes de resolução de problemas, associadas a uma imaturidade cognitiva geral. Isso leva normalmente a uma ação imediata, anterior a qualquer pensamento (o agir antes de pensar, característico de pacientes com o transtorno)". (ROHDE; MATTOS, 2003, p. 184).

${ }^{7}$ A Terapia Cognitivo-comportamental é sugerida pelos especialistas porque é nela que o terapeuta desenvolve a função de treinador do comportamento dos indivíduos. Os especialistas informam que o objetivo dessa terapia é "compreender melhor os sintomas e prejuízos do transtorno como decorrentes de uma doença". (ROHDE; MATTOS, 2003, p. 184). 
fim, destacamos a necessidade de se pensar uma escola que problematize os chamados "problemas de aprendizagem", criticando a produção teórica brasileira que tem como tema a medicalização da educação.

São essas considerações que pretendemos tratar nas próximas sessões deste trabalho, repensando as relações entre educação, instrumentalização $^{8}$ e medicalização da existência ${ }^{9}$.

\section{A MEDICALIZAÇÃO DA QUEIXA ESCOLAR}

Pesquisadora: A Susi tem o diagnóstico?

Mãe: Tem. A Susi passou por... Primeiro eu tive resistência em relação a essa possibilidade [...] daí eles [psicólogos] me indicaram um médico, que é psiquiatra infantil, daí esse psiquiatra pediu pra ela fazer testes com psiconeuro...

Pesquisadora: Neuropsicólogo?

Mãe: É. Neuropsicólogo. Ela fez os testes e ele constatou que era isso aí, que o diagnóstico era esse mesmo: TDAH. Daí ela passou a fazer tratamento, acompanhamento com psiquiatra. (SIGNOR; SANTANA, 2016, p. 141).

A crescente medicalização da existência humana ${ }^{10}$, particularmente da vida escolar, apresenta-se evidente nos discursos da mídia, na produção teórica brasileira de revistas especializadas e nas falas de pais e mães como na citada no início desta sessão.

\footnotetext{
${ }^{8}$ Esse conceito é tomado das reflexões desenvolvidas por Adorno e Horkheimer no livro intitulado "Dialética do esclarecimento". O referido resume, com riqueza, os elementos constitutivos da razão instrumental: "ela é razão no processo técnico, na operação, no saber aplicado. Reifica-se; coisifica-se. Eliminando toda a dubiedade do pensar através de sua unidimensionalidade [...]" (PUCCI, 1994, p. 24). Dito de outro modo, trata-se de uma racionalidade como expressão da capacidade do homem de ordenar a realidade pautada em fins e objetivos tecnicamente calculados previamente. Toda a ciência e a técnica se orientam para antecipar acontecimentos e prover as necessidades humanas. Todavia, tais necessidades são, muitas vezes, artificiais, no sentido de que funcionam como modelos de existência criados pela indústria cultural, determinando diversos aspectos da vida, como o intelectual, o social, o político, o econômico, o cultural, o educacional.

${ }^{9}$ Não se trata de criticar a medicação de doenças, muito menos de negar as bases biológicas do comportamento humano. $O$ que aqui apresentamos é uma contraposição em relação às tentativas de se transformar problemas de viver em sintomas patológicos ou de se entender a subjetividade pela via estrita dos aspectos orgânicos.

${ }^{10}$ A terminologia "Medicalização da vida" foi inicialmente utilizada por Ivan Illich, crítico da cultura moderna, em seu livro "A expropriação da saúde" (1975) para descrever a inserção crescente dos saberes médicos e seu aparato denominado de "progresso científico" em campos da vida individual que passam a ser submetidos a explicações e intervenções médicas. O autor acima citado apresenta como a racionalidade médica influencia as relações sociais, conceituando esse processo de "Medicalização da vida".
}

Essas concepções são corriqueiras no ambiente escolar, contribuem para a construção de práticas pedagógicas e produzem diagnósticos que, muitas vezes, chegam à escola antes do próprio estudante, ou a ele são fixados de tal modo que, na maioria das vezes, ele se sente impossibilitado de escapar a determinados padrões impostos pela medicalização da vida.

É possível considerar que seja por meio da reiteração dessas concepções que os saberes médicos se inserem na dinâmica do ambiente escolar e as práticas pedagógicas se apropriam de um tipo de racionalidade instrumentalizante que tem como objetivo "catalogar" aqueles que escapam às normas pré-estabelecidas pela escola.

0 termo medicalização ${ }^{11}$, segundo Moysés e Collares (1996), refere-se ao processo de transformar questões não médicas, eminentemente de origem social, educacional e política, em questões médicas, isto é, tentar encontrar no campo médico as causas e soluções para os problemas dessa natureza.

No que se refere ao transtorno de Déficit de Atenção e Hiperatividade (TDAH), esse é um fenômeno que é objeto de estudo de vários campos do conhecimento: Pedagogia, Fonoaudiologia, Linguística, Medicina ${ }^{12}$, Neuropsiquiatria, dentre outros. Apesar da contribuição desses outros campos de conhecimento, a definição diagnóstica parece ser de competência exclusiva da psiquiatra e suas implicações apresentam ressonâncias para a vida social e educacional dos estudantes.

De acordo com Moysés e Collares (2013, p. 44), "vivemos a Era dos transtornos. Uma época em que as pessoas são despossuídas de si mesmas e capturadas-submetidas na teia de diagnósticos-rótulos-etiquetas, antigos e novos,

\footnotetext{
${ }^{11}$ Nas palavras de Moysés e Collares (2013, p. 42): “Nas sociedades ocidentais, é crescente a translocação para o campo médico de problemas inerentes à vida, com a transformação de questões coletivas, de origem social e política, em questões individuais, biológicas. Tratar questões sociais como se biológicas iguala o mundo da vida ao mundo da natureza. Isentam-se de responsabilidades todas as instâncias de poder, em cujas entranhas são gerados e perpetuados tais problemas".

12 De acordo com Coelho (2012, p. 21), a medicina está ampliando o seu campo de ação para os mais diversos aspectos da existência. Nas palavras do autor: "o psiquiatra, agora, trata de praticamente todos os problemas humanos. As questões e dilemas éticos do indivíduo a cada dia menos tem a ver com a sua liberdade e poder de decisão - e mais com as dosagens bioquímicas de seu cérebro e com a indicação de fármacos. Da mesma forma, as sensações, emoções, percepções e estilos de pensar e de agir do indivíduo, a estética da existência, está se tornando da alçada das prescrições médicas. Hoje, tudo é medicalizável: tristeza, preguiça, estresse, transgressão, falta de concentração, indisciplina, perda da libido"
} 
cosmeticamente

reinventados".

Diante da medicalização da vida, comportamentos característicos de agitação, impulsividade, desatenção, hiperatividade, agressividade são manifestações mais corriqueiras de crianças candidatas aos diagnósticos do TDAH, apontadas pelos profissionais da saúde e da educação, além de pais e mães diariamente.

Diante da amplitude que caracteriza a temática, podemos questionar: por que muitos profissionais, incluindo os professores, tendem a suspeitar que uma criança tem $\operatorname{TDAH}^{13}$ ? O que está sendo tratado como patológico não seria a manifestação de um pensamento sufocado e neutralizado pela instrumentalidade científica? 0 TDAH não seria uma estratégia defensiva à experiência opressora dos modos de existir no espaço escolar?

Diante do exposto, a dimensão da instrumentalização técnica do pensar se impõe à prática pedagógica. E essa dimensão, presente no discurso pedagógico atual, estabelece uma lógica diversa daquela que leva em conta a dimensão formativa da educação e a impossibilidade de garantias e adequações da relação humana que a sustenta. Assim, a crença na intervenção do fármaco como solução reduz outras intervenções no trato pedagógico como potentes e transformadoras.

É a própria vida que seria preciso reinventar, mas a vida é uma palavra vaga e não se trata de tomar novamente Robinson por modelo; trata-se, outrossim, das instituições e, e, primeiro lugar, da família, da escola e do hospital. Em vez de revolucionar o ensino e sua estrutura, o Ocidente prefere, pelo contrário, remediar os efeitos das anomalias geradas por um ensino inadequado á nossa época. Remediar os

\footnotetext{
${ }^{13} \mathrm{Na}$ contemporaneidade, o debate sobre a medicalização da vida tem suas manifestações em outros países e em diversas áreas como a saúde, estética, esporte, direito, administração, dentre outros. No que se refere ao enfrentamento da lógica medicalizante, podemos citar movimentos sociais em todo o globo. De acordo com Ribeiro (2014, p. 14), podemos citar alguns: "Fórum sobre medicalização da educação e da sociedade (Brasil), Fórum infâncias (Argentina), StopDSM (Espanha), Le Collectif Pas de 0 de conduit (França), Círculo de estudos e intervenção na medicalização da educação".
}

efeitos significa, neste caso, encarregar a medicina de responder onde o ensino fracassou (MANNONI, 1988, p. 49).

A quantidade de indivíduos que tem recebido o diagnóstico de TDAH vem crescendo de forma preocupante. Ressaltamos abaixo alguns elementos dessa discussão.

Segundo Moysés e Collares (1996), nos EUA, houve um aumento significativo de $600 \%$ na produção e no consumo de metilfenidato entre os anos de 1990 e 1995.

De acordo com informações publicadas pelo Instituto Brasileiro de Defesa dos usuários de Medicamentos (IDUM), em 2010, a venda do medicamento Ritalina aumentou 1 616\% desde 2000. Foram consumidas 71000 caixas de Ritalina - substância utilizada em crianças e adolescentes com a pretensão de diminuir o chamado déficit de atenção/hiperatividade - e 739000 em 2004 (aumento de 940\%). Considerando os anos de 2003 e 2004, o crescimento foi de 51\%. Já em 2008, foram vendidas 1147000 caixas de metilfenidato. No ano de 2010, foram consumidas aproximadamente dois milhões de caixas $^{14}$.

Outro dado não menos importante é que o Brasil é, atualmente, o segundo maior consumidor de Ritalina do planeta (SIGNOR; SANTANA, 2016). Pela exposição anterior, notase que vivemos em uma sociedade "doente".

Se atentarmos para o conceito de saúde ${ }^{15}$ estabelecido pela OMS, notamos que tudo o que escapa a uma pretensa normalidade é classificado como patológico, logo, passível de controle e domesticação.

Os padrões são
delimitados com base em
uma concepção de
normalidade
convencionalmente
construída.
manifestações que se
desviam dos padrões
delimitados são
interpretados como fora
da normalidade,
consequentemente,

\footnotetext{
${ }^{14} \mathrm{Cf}$ : http//: www.idum.org.br. Acesso em: 9 jan. 2018.

${ }^{15}$ A OMS entende saúde como "um estado de completo bem-estar físico, mental e social, não consistindo somente na ausência de enfermidades ou de doenças". Assim, o conceito de saúde se transforma num projeto para se atingir uma espécie de bem-estar pleno. (SIGNOR; SANTANA, 2016).
} 
patológicas. Desse modo, a padronização e a classificação dos comportamentos produzem a distinção entre o normal e o patológico (RIBEIRO, 2014, p. 16).

A partir dessa conceituação, passam a ser elaboradas ações para a promoção da saúde mundial. Dela parte também a proposta de uma medicina que se centrará na busca incessante do bem-estar nos mais diversos aspectos, em que a ela é atribuída a "tarefa de legislar e normatizar o que é saúde e o que é doença, o que é saudável e o que não é". (MOYSÉS; COLLARES, 2013, p. 49) e, consequentemente, segregar - ou talvez silenciar - aqueles que não se "encaixam" nas normas estabelecidas.

Neste ponto da presente exposição, cabem alguns questionamentos: o que significa ser saudável na atualidade? Quais são as formas utilizadas pela medicina biotecnológica em relação à construção de um ideal de saúde perfeito e dos modos como lidamos com o sofrimento?

Como exposto anteriormente, assistimos a um exponencial aumento do número de diagnósticos no campo da medicina que engloba todos os aspectos da vida, de modo que um número maior de pessoas torna-se potencialmente "portador" de alguma patologia ${ }^{16}$.

\section{A MEDICALIZAÇÃO DA INFÂNCIA E SEUS EFEITOS NA ESCOLA}

"Ultimamente, venho sendo consumidor forçado de drágeas, comprimidos, cápsulas e pomadas que me levaram a meditar na misteriosa relação entre doença e o remédio... Ninguém sai de uma farmácia sem ter comprado, no mínimo cinco medicamentos prescritos pelo médico, pelo vizinho ou por ele mesmo, cliente. Ir à farmácia substitui hoje o saudoso hábito de ir ao cinema ou ao Jardim Botânico. [...]. Estou confuso e difuso, e não sei se jogo pela janela os

\footnotetext{
${ }^{16}$ Para uma rápida caracterização, o DSM II (1952/1968) catalogava um total de 182 categorias patológicas. Quando o DSM III surge, em 1980, esse número aumentou para 265 e 292 no DSM III - R/1987. Em 1994, foi lançado o DSM IV, que estabeleceu 297 categorias. Em 2000, esse número saltou para 374 com o DSM IV-TR. A publicação da nova edição do DSM V, em 2013, contou com 450 categorias diagnósticas. Percebemos um movimento crescente de classificação e de patologização da existência humana (MOYSÉS \& COLLARES, 1996).
}

remédios que médicos, balconistas de farmácia e amigos dedicados me receitaram, ou se aumento o sortimento deles com a aquisição de outras fórmulas que forem aparecendo, enquanto o Ministério da Saúde não as desaconselhar. E não sei, já agora, se se deve proibir os remédios ou o homem. Este planeta anda meio inviável".

"O homem e o remédio: qual o problema?"

Carlos Drummond de Andrade

Baseados em estudos teóricos de autores como Moysés e Collares (1996; 2013), Santos (1990), Barbosa e Silvares (1994), Signor e Santana (2016), Souza (1996) quando se trata da temática do TDAH, notamos a prevalência de uma grande procura por atendimento para crianças e adolescentes com "queixa escolar" em serviços de saúde que ofertam atendimentos gratuitos de saúde mental.

No Brasil, no período situado entre 2003 e 2007, a venda de ansiolíticos em farmácias cresceu $42 \%$ conforme levantamento da Anvisa (Agência Nacional de Vigilância Sanitária) com base nos dados apresentados pelo IMS Health. No ano de 2003, foram comercializados 17 milhões de unidades de antidepressivos; no ano de 2007 foram consumidas 24 milhões e em 2008 foram de 30 milhões.(BRASIL, 2013).

A Revista ISTOÉ, cuja edição data de 30 de janeiro de 2013 (ano 37, $n^{\circ}$ 2254) nos apresenta uma ideia interessante em relação a temática da medicalização.

A matéria de capa apresenta a seguinte "descoberta" científica: "A cura pelos genes: chega ao mercado o $1^{\circ}$ medicamento que torna saudável um DNA defeituoso e marca o início de uma nova era na medicina". A referida matéria anuncia uma nova era da farmacologia (não seria, talvez, um novo farmacolonialismo?) marcada pela terapia genética que antes era um terreno experimental e hoje se torna uma realidade. A autora do artigo destaca que "a droga é a esperança de uma vida sem sofrimento para milhares de pessoas". (OLIVEIRA, 2013, p. 70). Desse modo, justifica-se a hipótese de que crianças e adolescentes diagnosticáveis com TDAH são limitados em sua existência, fazendo com que os próprios professores os orientem ao encaminhamento médico para a prescrição de psicotrópicos.

Nessa perspectiva da medicalização de 
produção de diagnósticos de supostos transtornos, crianças e adolescentes são considerados como os únicos responsáveis pelo não acompanhamento dos conteúdos escolares. Os fatores relacionados ao contexto, como os da própria escola e da sociedade em geral, não são analisados. Camuflamse fatores políticos, econômicos,

administrativos, culturais, pedagógicos,

metodológicos, técnicos, relacionais, etc. enfim, negligenciam-se as situações contextuais históricas e sociais de produção da sociedade e de suas instituições sociais especificamente (RIBEIRO, 2014, p. 20).

Diante da amplitude que caracteriza a temática, notamos que as concepções medicalizantes da vida transmitem "achados científicos", adquirindo rapidamente imperativos de ação e verdades absolutas. Por meio da revisão de literatura sobre o tema aqui proposto, notamos que há um sutil abandono do espaço interior, das angústias subjetivas e dos conflitos psíquicos. Dito de outro modo, inúmeros estudos, como os realizados por Brown (2007), Barkley (2002), Hallowell \& Ratey (1999) apostam na chegada de um momento pós-biológico ou pósorgânico em que o corpo material será ínfimo diante dos avanços dos empreendimentos da genética, da robótica e da nanotecnologia, almejando libertar o ser humano da fragilidade do corpo, portador de enfermidades, sofrimentos e da morte, em que o simples uso de "pílulas mágicas" poderá alcançar uma pureza técnica.

Se atentarmos para a definição do TDAH presente na quinta edição do Manual Diagnóstico e Estatístico de Transtornos Mentais ${ }^{17}$ (conhecido

\footnotetext{
${ }^{17}$ Desde a sua primeira elaboração - 1952 - foram publicadas cinco revisões do DSM, sendo que a maior delas foi a do DSM - IV, cuja publicação ocorreu no ano de 1994, afirmam Signor e Santana (2016). O DSM - IV conceitua o TDAH como um padrão persistente de desatenção e/ou hiperatividade e apresenta uma divisão do transtorno de déficit de atenção em três subtipos: "predominantemente desatento; predominante hiperativoimpulsivo e tipo combinado" (DSM - IV, 1994). Com a nova publicação do DSM - $V$, algumas mudanças relativas ao TDAH foram introduzidas, apontando que é possível fazer o diagnóstico de TDAH
}

como DSM - V), publicado em 2013 pela Associação Psiquiátrica Americana, o TDAH é classificado como um transtorno do desenvolvimento neurológico e conceituado como "padrão persistente de desatenção e/ou hiperatividade-impulsividade que interfere com o funcionamento ou desenvolvimento" (AMERICAN PSYCHIATRIC ASSOCIATION, 2014, p. 33).

Para a formulação do diagnóstico, é necessário que se tenha 6 ou mais sintomas dos 9 apresentados para cada padrão. Exemplificando a consideração acima, os critérios diagnósticos listados no DSM - $\mathrm{V}$, no caso do padrão de desatenção, são: 1) dificuldade de prestar atenção a detalhes ou comete erros nas tarefas escolares; 2) apresenta dificuldade para manter a atenção em tarefas recreativas; 3 ) não segue instruções e não finaliza seus deveres escolares, 4) se distrai com facilidade, 5) com frequência, tem dificuldade para organizar tarefas e atividades, 6) com frequência evita, antipatiza ou reluta a envolver-se em tarefas que exijam esforço mental constante, 7) com frequência, perde coisas necessárias para tarefas ou atividades, 8) é facilmente distraído por estímulos alheios à tarefa, 9) com frequência, apresenta esquecimento em atividades diárias (AMERICAN PSYCHIATRIC ASSOCIATION, 2014, p. 33-34).

As anotações anteriores revelam comportamentos e atitudes que qualquer criança, adolescente ou até mesmo um adulto podem apresentar de forma frequente em diversas situações. Então, podemos questionar: como padronizar um diagnóstico de um transtorno neurológico com base nesses "sintomas" em indivíduos tão díspares? Desse ponto de vista o "padrão persistente" de sintomas implica, na verdade, em uma padronização normativa do que está cientificamente legitimado o fazer medicalizante.

Frente a essas colocações, o coletivo de alunos/as tem sido alvo de um aumento vertiginoso de emissão de diagnósticos de supostos transtornos como justificativa para a

\footnotetext{
mesmo na presença de um quadro de autismo. Outra modificação foi que o início dos sintomas deve estar presente antes dos 12 anos, alterando o estabelecido anteriormente, que era dos sete anos. 0 termo "subtipos" foi substituído por "apresentações", mantendo-se as subdivisões de predomínio desatento, impulsivo e combinado (DSM - V, 2014). O DSM - V estabeleceu uma classificação de gradação para o TDAH em leve, moderado e grave conforme a intensidade dos sintomas e o nível de prejuízo que acarreta à vida da pessoa.
} 
explicação das dificuldades escolares vivenciadas pelos estudantes.

A literatura revisada apresenta a maneira como os envolvidos diretamente na educação escolar concebem o TDAH.

Em uma pesquisa de campo realizada por Leonardo e Suzuki (2016), com dez professores de três escolas públicas do ensino fundamental no estado do Paraná, ficou nítido como os educadores associam desatenção com doença. Dentre as questões que compuseram o instrumental de coleta de dados utilizados pelas autoras, apresentamos a primeira com as respectivas respostas de alguns professores. Eis a questão: "o que leva o aluno a ser encaminhado ao médico?". As possíveis respostas são citadas abaixo, identificadas por P1, P4, P7 e P10:

"Geralmente, é o comportamento que a gente vê que não é adequado para a sala de aula" (P1);

"Tem aluno que não consegue se concentrar na atividade. Esses alunos geralmente começam uma atividade, mas não têm um meio e não finalizam" (P7);

"Não é questão de não estar prestando atenção na aula porque é normal, mas porque não quer prestar atenção, não quer fazer alguma coisa, ou dorme" (P10);

"A gente chega num momento em que não tem como mais conversar com o aluno e tem que mandar para a coordenação. $\mathrm{E}$ a repetição desses fatos faz com que haja o encaminhamento para o médico" (P4). (LEONARDO; SUZUKI, 2016, p. 48-49).

A maioria das falas apresentadas anteriormente revela que muitos profissionais da educação demonstram-se incapacitados para lidar com as questões da existência humana. Assim, indisciplina, comportamentos desatentos, impulsividade são interpretados como manifestações psicopatológicas. Desse modo, o melhor "remédio" encontrado para essas "mazelas" é o encaminhamento ao médico, almejando um possível tratamento para a "patologia" apresentada.

A entrada da medicina no ambiente escolar torna-se, assim, a "pedra filosofal" para responder aos problemas de comportamentos dos alunos indisciplinados, mal-educados, agressivos e desatentos. Como uma das formas de procurar

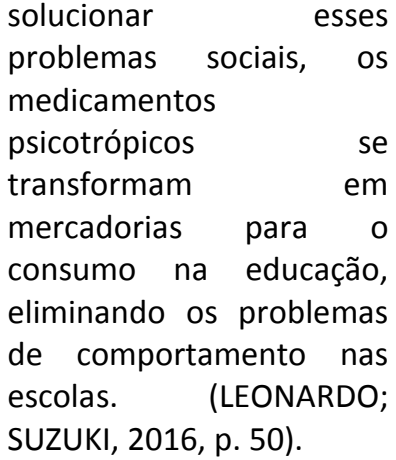

Note que tais observações ratificam que as dificuldades cognitivas enfrentadas pelas crianças nas escolas têm sido entendidas como transtornos/patologias/distúrbios. Essas indicações são consideradas como exclusivamente determinadas pela constituição orgânica/psicológica do estudante. Sem aprofundar outras questões de entendimento da possível não aprendizagem dos estudantes, as dificuldades são concebidas como um fenômeno meramente individual apartadas do contexto sócio-histórico no qual o indivíduo está inserido.

Camuflam-se fatores
políticos, econômicos,
administrativos, culturais,
pedagógicos,
metodológicos, técnicos,
relacionais, etc. Enfim,
negligenciam-se as
situações contextuais
históricas e sociais de
produção da sociedade e
de suas instituições sociais
especificamente (RIBEIRO,
2014, p. 20).

Mas, a medicalização da queixa escolar não para por aqui.

\section{A impossibilidade da medicalização do processo educativo}

No que se refere ao diagnóstico preciso do TDAH, os teóricos do debate medicamentoso organicista recomendam que, de forma preliminar, uma anamnese seja realizada junto às crianças/adolescentes, seus pais e professores através de escalas objetivas padronizadas, como o SNAP - IV, por exemplo. Uma avaliação neurológica (por meio de exames de neuroimagem) também é recomendada, dentre outras. Nesta análise, nos deteremos na discussão do SNAP - IV por se referir a um 
instrumental específico utilizado nas escolas, afirmam Moysés e Collares (2013).

O SNAP - IV é um instrumento diagnóstico utilizado nas escolas para "detectar" sintomas de TDAH. Esse instrumental está disponível no site da $\mathrm{ABDA}^{18}$ para que os pais e professores possam fazer uma espécie de diagnóstico preliminar com base na anamnese. Entretanto, o diagnóstico definitivo só pode ser feito por alguns profissionais que têm cadastro no site, como médicos, psicólogos e fonoaudiólogos, os quais pagam anuidade para manter o cadastro ativo. Dentre os pré-requisitos necessários para a aprovação do cadastro, está a exigência de dois anos de atendimento a pessoas com TDAH e a participação dos profissionais nos eventos promovidos pela ABDA.

Trata-se de um instrumental composto por um questionário com 18 itens, sendo que os 9 primeiros referem-se à desatenção e os últimos, à hiperatividade e à impulsividade. Para cada item, o indivíduo deve responder "nem um pouco", "só um pouco", "bastante" e "demais".

O diagnóstico é fechado caso a pessoa responda "bastante" ou "demais" a seis perguntas de cada item, sendo o diagnóstico feito por predominância: no caso do primeiro bloco, há déficit de atenção; já no segundo bloco, hiperatividade e impulsividade.

Desse modo, ao estudante identificado com o TDAH deveria ser dispensado alguns cuidados na escola, tais como "tratamento reeducativo psicomotor, deve ser colocado na primeira fila da sala de aula próximo à professora e longe da janela, ou seja, em local onde tenha menor probabilidade de distrair-se" (ROHDE et al, 2000, p. 9-10).

Na mesma direção do que foi proposto pelos psiquiatras acima citados, Souza e Ingberman (2000, p. 4) afirmam que "um tratamento mais eficaz para um TDAH envolve a combinação de medicamentos e psicoterapia". Também defendem a abordagem cognitivocomportamental (as chamadas terapias cognitivo-comportamentais - $\mathrm{TCC}^{\prime} \mathrm{s}^{19}$ ), com

\footnotetext{
${ }^{18}$ Associação Brasileira do Déficit de Atenção. Cf: http//: www.tdah.org.br. Acesso em: 14 fev. 2018.

19 As chamadas terapias comportamentais são, atualmente, a tecnologia médica mais utilizada nos EUA e amplamente divulgada no Brasil. Castel (1987) em "A gestão dos riscos" pesquisou as técnicas médico-psicológicas de intervenção sobre o sofrimento de modo a analisar como se desenvolveram, na cultura atual, as "tecnopsicologias". Diante do assinalado, o autor analisa o surgimento de terapias comportamentais como maneira cada vez mais difundida de tratar o sofrimento. Para o citado autor, a terapia comportamental seduz por sua simplificação e sua eficácia no
}

enfoque no treinamento de autoinstrução, treinamento na resolução de problemas sociais e autorreforço. (SOUZA; INGBERMAN, 2000; ROHDE et al, 2000).

Segundo os teóricos do debate medicamentoso na escola, o principal tratamento para o TDAH é o psicotrópico. Cabe uma observação nesse aspecto.

Moysés e Collares (2010, p. 197) apontam para os limites em se biologizar as questões sociais por deslocar "[...] o eixo de uma discussão político-pedagógica para causas e soluções pretensamente médicas, portanto, inacessíveis à educação. A isto, devemos chamar medicalização do processo ensino-aprendizagem [...]".

Como mencionado anteriormente, a medicalização dos processos educacionais isenta os professores da responsabilidade por esse contexto da não aprendizagem "[...] criando ou ampliando um novo mercado de trabalho para avaliar, diagnosticar e tratar doenças no processo ensino-aprendizagem". (RIBEIRO, 2014, p. 25).

Para os teóricos do TDAH do campo medicamentoso instrumental, resta ao indivíduo classificado com tal transtorno submeter-se ao tratamento farmacológico ${ }^{20}$.

tratamento de vários elementos: reações de fobia, ansiedade, depressões, pesadelos, isolamentos, transtornos, entre outros. De acordo com Castel (1987), um dos elementos das chamadas terapias comportamentais é permitir indicações para quase tudo sem que tenhamos que nos colocar problemas metafísicos ou políticos sobre essas intervenções. Assim, é até recomendado que não se pense muito nessas questões, uma vez que a objetividade se torna livre para buscar sua eficácia. Segundo o mesmo autor, nesse tipo de intervenção não há uma procura pela totalidade da experiência da vida do indivíduo em sofrimento para além do possível aspecto "patológico". Segundo Furtado (2014, p. 133), “esses tratamentos se propagam sempre sob o estandarte do bem-estar e se consumam através da desarticulação de um complexo mais amplo da história pessoal e social da pessoa".

${ }^{20}$ Para Rohde et al (2000), medicamentos à base de metilfenidato podem ser muito eficazes para dirimir os sintomas de desatenção na medida em que aumentam a liberação de dopamina e noradrenalina no cérebro. Ao aumentar a disponibilidade dos neurotransmissores, o psicotrópico estimula a função das áreas cerebrais responsáveis pelo comportamento inibitório. Schwartzman (2008) mostra-se favorável ao uso do psicotrópico e às terapias comportamentais. Sugere algumas orientações para pais e professores, tais como uso de agendas, menor quantidade de alunos na sala de aula, regras claras e trabalhos menos extensos. Segundo o neurologista, a maioria dos pacientes responde positivamente, desde que as dosagens sejam adequadas e prescritas pelo médico. Nas palavras do autor: "o tratamento farmacológico pode ser utilizado em conjunto com algum desses procedimentos - TCC's ou isoladamente" (SCHWARTZMAN, 2008, p. 110). As posições tomadas pelo autor no que tange à escola são as mais variadas possíveis, indo desde a diminuição de estímulos ambientais à produção de comportamentos padronizados. Em uma posição contrária, Signor e Santana (2016) teceram críticas aos apontamentos da postura medicamentosa instrumental na escola, afirmando que alguns benefícios como provas orais, maior tempo para realizar atividades, atendimento especializado e professor auxiliar poderiam servir para acentuar as diferenças. 
A postura por nós adotada nesse debate é de crítica e de evidência de seus limites.

De acordo com o Rohde et al (2000), o TDAH é diagnosticável com base em critérios operacionais claros e bem definidos, provenientes do DSM - V e do CID - 10. Em relação às intervenções no âmbito pedagógico, segundo Rohde et al (2000, p. 9 - 10), alguns quesitos devem ser destacados no que se refere ao desempenho do aluno quando indicam alguns "procedimentos" a serem adotados pelos professores:

[...] sala de aula bem
estruturada, com poucos
alunos; rotina diária
consistente e ambiente
escolar previsível;
estratégias de ensino ativo
que incorporem a
atividade física, tarefas
curtas e explicadas passo a
passo; atendimento
individualizado; aulas de
reforço escolar;
acompanhamento
psicopedagógico centrado
na forma do aprendizado
e, em alguns casos,
tratamento reeducativo
psicomotor.

Tendo em vista esse panorama, os adeptos do debate medicamentoso caminham no sentido contrário ao da pluralidade e da diversidade das manifestações humanas.

De acordo com os críticos do TDAH, ao se criar um discurso específico para identificar tal transtorno, provavelmente ele não favorecerá o desenvolvimento das potencialidades (cognitivas, afetivas, emocionais, artísticas, críticas) de uma criança, "uma vez que as dificuldades escolares dos alunos, muitas vezes, não são uma questão de doença: há aspectos relacionados ao letramento, às práticas de leitura e da família, do sujeito e, sobretudo, dos docentes". (SIGNOR; SANTANA, 2016, p. 110).

Signor e Santana (2016), Moysés e Collares (2010), Ribeiro (2014) consideram que o debate educacional brasileiro sobre os diagnósticos do TDAH ignoram os indicadores sócio-históricos.

Observadas essas constatações, os questionamentos dos críticos encaminhados aos adeptos da medicação do processo de ensino e aprendizagem (concepção organicista medicalizante) são: de qual escola estamos falando? De qual ensino? O TDAH seria uma resistência aos processos pedagógicos impostos aos estudantes? O TDAH se resumiria a um problema de falta de dopamina no cérebro como apontam alguns pesquisadores da vertente medicalizante? Uma pílula que promete modificar comportamentos reprováveis pela escola gera apenas um bom desempenho?

Como vemos, são questionamentos que extrapolam a posição a favor da medicalização presente na educação escolar, uma vez que os dados que fundamentam a discussão da legitimação médica e biológica do TDAH são oriundos das investigações neurológicas e da pesquisa molecular e genética e, portanto, sem aprofundamento das questões sócio-históricas. Através deles - dos dados - a concepção medicalizante dominante afirma ser possível demonstrar que o transtorno existe porque seus fatores biológicos foram descobertos.

O que está em pauta nessa discussão é evidenciar a inadequada aplicação do viés do pensamento meramente medicamentoso às questões educacionais. Dito de outro modo, a escola deve repensar suas propostas formativas, preocupando-se em refletir sobre as possibilidades do existir e do experienciar contemporâneo.

\section{CONSIDERAÇÕES INCONCLUSIVAS}

A partir de estudos de alguns autores como Moysés \& Collares (2010), Garrido \& Moysés (2010), Signor \& Santana (2016) fica constatada a necessidade de se problematizar as concepções medicalizantes na educação escolar.

A análise aqui proposta evidenciou como certas concepções e práticas medicalizantes e instrumentalizantes do pensar acabam reduzindo os problemas de ordem social, política e econômica a problemas biológicos ou familiares, limitando uma discussão sobre a complexidade do processo de ensino e de aprendizagem.

O Transtorno de déficit de atenção e hiperatividade é alvo de crítica de psiquiatras, psicólogos, professores, familiares, legisladores, entre outros. Uma crítica diz respeito ao diagnóstico. Os principais sintomas do TDAH são vagos e virtualmente indistinguíveis de problemas cotidianos, 
além de ser contexto dependentes (por exemplo, uma criança pode ser desatenta e hiperativa ao assistir aula e não enquanto conversa com seus amigos). Além disso, o diagnóstico não pode ser testado por exames médicos concretos, o que estabelece o TDAH como uma síndrome e não como uma doença, ouse já, como um conjunto de sinais e sintomas que pode ser resultado de várias causas, geralmente desconhecidas, [...] cujo rótulo traz consequências desastrosas por se tornar, muitas vezes, uma profecia autorrealizadora. (LEONARDI et al, 2010, p. 11-116).

De acordo com Caliman (2008), as investigações realizadas no campo citado desenvolvem-se no sentido de não apenas apontar os prejuízos que o TDAH causa ao indivíduo, mas, sobretudo, de afirmar que este é determinado por fatores biológicos, genéticos e cerebrais. Por assim dizer, o discurso da neuropsiquiatria dominante entende que "o diagnóstico do TDAH é real porque em certa medida, é visível e biológico, e descreve uma condição maligna". (CALIMAN, 2008, p. 565).

Outro elemento preocupante nesse debate ocorrido especialmente no âmbito escolar é o crescente número de crianças que estão sendo diagnosticadas com TDAH e medicalizadas.

Conforme salientado anteriormente, Moysés \& Collares (2010, p. 197) apontam os limites em biologizar as questões sociais por deslocar "o eixo de uma discussão políticopedagógica para as causas e soluções pretensamente médicas, portanto, inacessíveis à educação".

Todos os fatores aqui apontados e que contribuem para a precarização do trato pedagógico possuem contradições que puderam ser refletidas pelos argumentos apontados ao longo deste artigo.

O elemento mais grave do processo de medicalização é que ele serve exclusivamente para confirmar suspeitas de professores e médicos. As crianças passam a serem vistas como deficientes, incapazes de aprender, e são submetidas ao consumo de doses aviltantes de drogas psicotrópicas, vivendo de diagnósticos e remédios. $\mathrm{E}$ esses, por certo, é que não são capazes de ensinar alguém a ler ou escrever. (GARRIDO; MOYSÉS, 2010, p. 158).

Tais argumentos evidenciam o que Crochik \& Crochik (2010, p. 182) postulam a respeito da medicalização escolar. Se a escola não consegue dar conta dos estudantes que não respondem prontamente às tarefas que a eles são exigidas, os alunos diagnosticados com TDAH podem se desinteressar ainda mais pelos conteúdos ministrados em que "a possibilidade de serem discriminados e ocuparem o lugar de fracassados na sala de aula os tornariam ainda mais resistentes".

O interessante de se notar é que as relações dos envolvidos diretamente com educação se empobrecem, pois, os professores, que deveriam ser os responsáveis por analisar e se prontificar a entender as dificuldades enfrentadas por seus escolares, passam a ser mediadores ao encaminharem aqueles considerados com "problemas" de aprendizagem aos profissionais da saúde.

De certo modo, essa atitude de muitos professores reduz a angústia deles, ou seja, em vez de promover uma discussão política e pedagógica de mudanças significativas no sistema educacional, reduz-se o problema de aprendizado a uma questão individual, negando outros fatores geradores da não aprendizagem escolar, afirmam Signor e Santana (2016).

Assim, muito se tem falado sobre o fenômeno do TDAH, mas são poucos os envolvidos com um debate crítico a respeito dessa realidade no campo educacional. Tratar desse assunto tem sido uma atividade desafiadora. Assim, “a 'caça aos doentes' apenas contribuirá para que a instituição escolar se legitime de vez como espaço de exclusão" (SIGNOR; SANTANA, 2016, p. 110). 
Colaborando com a nossa postura crítica em relação aos discursos medicalizantes na educação escolar, Chauí (2014) aponta que aquele que possui um saber determinado (o professor, o médico, o engenheiro, o administrador, etc.) institucionalmente reconhecido, adquire o direito de falar e agir pelo outro, desconsiderando-o da sua posição de sujeito. Segundo a própria autora, o discurso competente transforma-se em um exercício de dominação, onde os competentes são aqueles que operam por um saber científico, verdadeiro, rígido e os não competentes são aqueles que se tornam submetidos aos supostos saberes dominantes.

Ao pensar sobre os saberes da/na infância, Larrosa (2002, p. 23) nota que existem inúmeras situações envolvendo a criança que objetivam dominá-la, capturá-la. Segundo o autor, "podemos abrir um livro de Psicologia infantil e saberemos de suas satisfações, de seus medos, de suas necessidades, de seus peculiares modos de sentir e de pensar", pouco restando ao indivíduo a possibilidade de entrar em contato com os seus próprios medos, sofrimentos, contradições, resistências e possibilidades do existir.

De modo geral, a partir da análise da literatura crítica da medicalização da queixa escolar sobre o TDAH, notamos o quanto o saber médico adentrou-se no campo escolar e o quanto o processo de normalização da medicalização torna-se a única forma encontrada pelos professores para se eximirem da árdua tarefa de experienciar $\mathrm{o}$ ato educativo. Eis aqui a necessidade do oportuno debate crítico sobre o TDAH.

Notamos que, cada vez mais, se torna difícil para a escola controlar as crianças nas salas de aulas. É muito complexo solicitar às crianças que permaneçam oito horas sentadas em carteiras padronizadas ouvindo um professor, sendo que elas são mais estimuladas quando interagem com jogos eletrônicos em aplicativos em suas telas de celulares, tablets e computadores. Acreditamos que um critério vago e impreciso pautado em classificações como "pouco", "demais" não pode explicitar com veracidade e praticidade um diagnóstico que marcará a vida de uma criança. Professores sobrecarregados pelas escolas, currículos obsoletos, didáticas reificadoras, tudo isso aumenta o desinteresse e a dificuldade em prestar atenção na aula. Desse modo, a partir das conclusões de Signor e Santana (2016), Crochik \& Chochik (2010), Coelho (2012), Bassani \& Bleidão (2015), Garrido \& Moisés (2010), Moysés \& Collares (1996), podemos apontar que um possível entendimento sobre o TDAH seria uma estratégia defensiva à experiência opressora dos modos de existir no espaço escolar.

Para os autores acima referenciados, a redução de nossa subjetividade em termos neuroquímicos e farmacológicos abre espaço para o abandono da dimensão simbólica de nossa constituição como indivíduos, limitando nossa condição crítica em relação ao contexto histórico, político, cultural e educacional o qual estamos inseridos. Em Guarido (2008, p. 103-104), o aspecto da medicalização da vida nos afasta da ideia de que convivemos com uma "dimensão do impossível, ou seja, não há garantias para o futuro, não há garantias de satisfação, não há antecipação possível daquilo que um encontro possa nos fazer viver, e isso não coincide com impotência". De forma instrumental, a prática pedagógica se torna pautada no controle da vida cotidiana, numa prática de hábitos meramente instrumentais. Como a medicalização assume uma posição de ser instrumento para que o aprendizado ocorra, estamos diante de uma perspectiva técnica que "reduz a potência do encontro humano como formativo, abrindo espaço, no campo da educação, para que esta seja reduzida a uma técnica de estimulação das habilidades e competências". (GUARIDO, 2008, p. 102).

Diante de toda a amplitude que caracteriza a temática, argumentamos que é preciso recusar as explicações totalizadoras que aparecem com certa frequência nas pesquisas científicas, nas estatísticas, nos discursos para mudarmos a "lente" com que enxergamos o fazer pedagógico. É preciso desconfiar das concepções simplificadoras do pensar e do experienciar humanos.

Problematizamos, neste artigo, os impasses de se relacionar "doença" a "nãoaprendizagem" na escola contemporânea.

No campo escolar, a reflexão sobre os modos de ensinar, técnicas e metodologias pedagógicas dificilmente são questionadas. Nosso intuito aqui está no interesse de expor o fenômeno da medicalização como algo sério a ser discutido, além de propor reflexões para se pensar a escola atual.

Diante desse panorama, é fundamental repensarmos as práticas pedagógicas discutindo 
qual é a função da escola contemporânea. E mais, é necessário questionar qual tipo de indivíduo estamos formando e para qual sociedade. Tudo indica que a escola deve ressignificar suas propostas formativas, problematizando e desconstruindo concepções que limitam as formas da existência e da experiência humana.

\section{REFERÊNCIAS}

ANDRADE, Carlos D. de. O homem e o remédio: qual o problema? Disponível em: $<$ http://cadernodefilosofias.blogspot.com/search ?q=rem\%C3\%A9dio>. Acesso em: 28 fev. 2018.

AMERICAN PSYCHIATRIC ASSOCIATION. Guia de Consulta dos critérios diagnósticos do DSM - V, Virginia, USA: APA, 2014.

BRASIL. MINISTÉRIO DA SAÚDE. AGÊNCIA DE VIGILÂNCIA SANITÁRIA. Resolução-RDC no67, de 8 de outubro de 2007. Diário Oficial da União, Brasília, DF, 09 de outubro de 2007.

BARBOSA, João Coelho; SILVARES, Emanoel. Uma caracterização preliminar das clínicas-escola de Fortaleza. Estudo de Psicologia, v. 11, n. 3, p. 5056, 1994.

BARKLEY, Russell A. Transtorno de déficit de atenção/hiperatividade (TDAH): guia completo e autorizado para os pais, professores e profissionais da saúde. Porto Alegre: Artmed, 2002.

BARROS, José A. C. de. Ampliando espaços para a "medicalização": instrumento para desfrute de melhores níveis de vida? In: CAPONI, Sandra et. al. Medicalização da vida: ética, saúde pública e indústria farmacêutica. Palhoça: Unisul, 2010, p. 89-95.

BASSANI, Elisabete; BLEIDÃO, Mirela Santos. A medicalização do fracasso escolar em escolas públicas municipais de ensino fundamental de Vitória/ES. In: REUNIÃO NACIONAL DA ANPED, 37., 2015, Florianópolis. Anais... Florianópolis: UFSC, 2015. p. 73-82.

BEZERRA JR., Benilton. A psiquiatria e a gestão tecnológica do bem-estar. In: FREIRE FILHO, João (Org). Ser feliz hoje: reflexões sobre o imperativo da felicidade. Rio de Janeiro: Ed. FGV, 2010, p. 117-134.
BROWN, Thomas E. Transtorno de déficit de atenção: a mente desfocada em crianças e adultos. Porto Alegre: Artmed, 2007.

CALIMAN, Luciana Vieira. O TDAH: entre as funções, disfunções e otimização da atenção. Psicologia em estudo, Maringá/ PR, v. 13, n. 03, 2008, p. 559-566.

CASTEL, Robert. A gestão dos riscos: da antipsiquiatria a pós-psicanálise. Rio de Janeiro: Editora Francisco Alves, 1987.

CHAUÍ, Marilena. A ideologia da competência. In: ROCHA, André (Org.). Escritos de Marilena Chauí. São Paulo: ed. Fundação Perseu Abramo, 2014.

COELHO, José Ramos. A tragicomédia da medicalização: a psiquiatria e a morte do sujeito. Natal, RN: MJCM, 2012.

CROCHIK, José Leon; CROCHIK, Nicole. A desatenção atenta e a hiperatividade sem ação. In: CONSELHO REGIONAL DE PSICOLOGIA DE SÃO PAULO. Medicalização de crianças e adolescentes: conflitos silenciados pela redução de questões sociais a doenças de indivíduos. São Paulo: Casa do Psicólogo, 2010, p. 179-191.

FURTADO, Mariana A. O lugar do sofrimento na cultura contemporânea: patologização do malestar e medicalização da vida. 2014. Dissertação (Mestrado em Psicologia) - Universidade Federal do Rio de Janeiro, Centro de Filosofia em Ciências humanas.

GARRIDO, Juliana; MOYSÉS, Maria. Um panorama nacional dos estudos sobre medicalização da aprendizagem de crianças em idade escolar. In: CONSELHO REGIONAL DE PSICOLOGIA DE SÃO PAULO. Medicalização de crianças e adolescentes: conflitos silenciados pela redução de questões sociais a doenças de indivíduos. São Paulo: Casa do Psicólogo, 2010, p. 149-161.

GUARIDO, Renata L. 0 que não tem remédio, remediado está: medicalização da vida e algumas implicações da presença do saber médico na educação. 2008. Dissertação (Mestrado em Educação). Universidade de São Paulo. Faculdade de Educação. São Paulo.

HALLOWELL, Edward; RATEY, John. Tendência à distração: identificação e gerência do distúrbio 
de atenção (DDA) da infância à vida adulta. Rio de Janeiro: Rocco, 1999.

ILLICH, Ivan. A expropriação da saúde: nêmesis da medicina. Rio de Janeiro: Nova Fronteira, 1975.

LARROSA, Jorge. Notas sobre a experiência e o saber da experiência. Revista Brasileira de Educação, São Paulo, n. 19, jan./abr. 2002, p. 2028.

LASCH, Christopher. A cultura do narcisismo. Rio de Janeiro: Imago, 1983.

LEONARDI, Jan; RUBANO, Denise; ASSIS, Fátima. Subsídios da análise do comportamento para avaliação de diagnóstico e tratamento do transtorno de déficit de atenção e hiperatividade (TDAH) no âmbito escolar. In CONSELHO REGIONAL DE PSICOLOGIA DE SÃO PAULO. Medicalização de crianças e adolescentes: conflitos silenciados pela redução de questões sociais a doenças de indivíduos. São Paulo: Casa do Psicólogo, 2010, p. 112-130.

LEONARDO, Nilza S. T.; SUZUKI, Mariana A. Medicalização dos problemas de comportamento na escola: perspectivas de professores. Fractal: Revista de Psicologia, v. 28, n. 1, p. 46-54, jan./abr. 2016.

MANFRÉ, Ademir Henrique. Eu sou agitado/a. Sintoma de TDAH? Revista do centro de Educação da UFSM. 2017, (no prelo)

MANNONI, Maus. Educação impossível. Rio de Janeiro: F. Alves, 1988.

MOYSÉS, Maria Aparecida; COLLARES, Cecília. A. Preconceitos no cotidiano escolar: ensino e medicalização. São Paulo: Cortez: Campinas, 1996.

Dislexia e TDAH: uma análise a partir da ciência médica. In: CONSELHO REGIONAL DE PSICOLOGIA DE SÃO PAULO. Medicalização de crianças e adolescentes: conflitos silenciados pela redução de questões sociais a doenças de indivíduos. São Paulo: Casa do Psicólogo, 2010, p. 71-110.

Medicalização: o obscurantismo reinventado. In: MOYSÉS, M.; COLLARES, C.;
RIBEIRO, M. (Org.). Novas capturas, antigos diagnósticos na era dos transtornos: memória do Il seminário internacional educação medicalizada: dislexia, TDAH e outros supostos transtornos. Campinas, SP: Mercado das Letras, 2013, p. 4164.

OLIVEIRA, Monique. A cura pelos genes: chega ao mercado o primeiro medicamento que torna saudável um DNA defeituoso e marca o início de uma nova era da medicina. Revista ISTOÉ, v. 37, n. 2254,2013 . p. 69-71.

PUCCI, Bruno (Org.). Teoria Crítica e educação: a questão da formação cultural na Escola de Frankfurt. Petrópolis, RJ: Vozes, 1994.

RIBEIRO, Maria. A medicalização da educação na contramão das diretrizes curriculares nacionais da educação básica. Revista Entreideias, Salvador, v. 3, n. 1, p. 13-29, jan./jun. 2014.

ROHDE, Luís Augusto. et al. Transtorno de déficit de atenção/hiperatividade. Revista brasileira de Psiquiatria, v. 22, n.2, 2000, p. 7-11.

ROHDE, Luís Augusto; MATTOS, Paulo (orgs.). Princípios e práticas em transtorno de déficit de atenção/hiperatividade. Porto Alegre: Artmed, 2003.

SANTOS, Manoel Antônio dos. Caracterização da clientela de uma clínica psicológica na prefeitura de São Paulo. Arquivos brasileiros de Psicologia, v. 40, p. 79-94, 1990.

SIGNOR, Rita; SANTANA, Ana Paula. TDAH e medicalização: implicações neurolinguísticas e educacionais do Déficit de Atenção/Hiperatividade. São Paulo: Plexus, 2016.

SOUZA, Eneida Maria; INGBERMAN, Y. K. Transtorno de déficit de atenção e hiperatividade: características, diagnósticos e formas de tratamento. Interação em Psicologia, v. 4, p. 23-37, jan./dez. 2000.

SOUZA, Maria Proença Rebello. A queixa escolar e a formação do psicólogo. 1996. Tese (Doutorado em psicologia) Instituto de Psicologia, Universidade de São Paulo, São Paulo, 1996.

Formação do psicólogo para
atendimento a problemas de aprendizagem: 
desafios e perspectivas. Estilos da clínica, v. 5, n. 9, p. 134-154, 2000.

SCHWARTZMAN, José Salomão. Transtorno de déficit de atenção. 3. ed. São Paulo: Memnom edições científicas, 2008.

Recebido para publicação em: 26/02/2018

Revisado em: 12/05/2018

Aceito em: 26/07/2018 